\title{
Review Article \\ Current and Potential Applications of Host-Defense Peptides and Proteins in Urology
}

\author{
Joey Chor Yee Lo and Dirk Lange \\ The Stone Centre at Vancouver General Hospital, Department of Urologic Sciences, University of British Columbia, \\ 2660 Oak Street, Vancouver, BC, Canada V6H $3 Z 6$ \\ Correspondence should be addressed to Dirk Lange; dirk.lange@ubc.ca
}

Received 10 August 2014; Revised 21 October 2014; Accepted 24 October 2014

Academic Editor: Joel E. López-Meza

Copyright ( $\odot 2015$ J. C. Y. Lo and D. Lange. This is an open access article distributed under the Creative Commons Attribution License, which permits unrestricted use, distribution, and reproduction in any medium, provided the original work is properly cited.

\begin{abstract}
The use of antibiotics has become increasingly disfavored as more multidrug resistant pathogens are on the rise. A promising alternative to the use of these conventional drugs includes antimicrobial peptides or host-defense peptides. These peptides typically consist of short amino acid chains with a net cationic charge and a substantial portion of hydrophobic residues. They mainly target the bacterial cell membrane but are also capable of translocating through the membrane and target intracellular components, making it difficult for bacteria to gain resistance as multiple essential cellular processes are being targeted. The use of these peptides in the field of biomedical therapies has been examined, and the different approaches to using them under various settings are constantly being discovered. In this review, we discuss the current and potential applications of these host-defense peptides in the field of urology. Besides the use of these peptides as antimicrobial agents, the value of these biological molecules has recently been expanded to their use as antitumor and anti-kidney-stone agents.
\end{abstract}

\section{Introduction}

The use of antibiotics can be dated back to the 1930s, when the sulfonamide Prontosil was introduced as the first commercially available antibiotic [1]. Several other classes of antibiotics emerged soon after, and by the 1940s, the "golden age of antibiotics" began with the introduction of penicillin [2]. In 1967, the use of antibiotics seemed so promising that the United States surgeon, William H. Stewart, even stated "...we had essentially defeated infectious diseases and could close the book on them..." [3]. However, although this statement looked true at that time, it was soon refuted when pathogenic bacteria with resistance against conventional antibiotics become increasingly prominent by the end of the 20th century; bacteria had gained resistance to multiple drugs [4]. The rise in multidrug resistant (MDR) bacteria became alarming, with a prevalence rate increase of $57 \%$ from the 1950s to the 2000s, with more resistance observed towards drugs that had been used for humans and animals for the longest time [4-6]. With MDR pathogens becoming a leading cause of nosocomial infections, and with the lack of novel, effective antibiotics, there is an urgent need to discover alternative drugs to control bacterial infections [4].

Antimicrobial peptides (AMPs) are ancient defense molecules of the innate immune system that has gained substantial attention over recent years [4, 7]. These peptides are found within a wide variety of species, including bacteria, insects, fungi, amphibians, birds, crustaceans, fishes, mammals, and humans, and can be obtained from many different sources, such as neutrophils, macrophages, and epithelial cells [7-9]. Similar to many conventional antibiotics, they have broad spectrum activity against a wide range of microorganisms, including both Gram-positive and Gramnegative bacteria, fungi, viruses, yeast, and protozoa $[7,10$, 11]. However, unlike current antibiotics, these AMPs have multiple sites as targets rather than single genes or proteins [4]. Although these peptides are mainly known for their ability to disrupt the cell membrane of target organisms, they are also known for their ability to translocate through the cell membrane and alter other essential cellular activities and promote immune responses, including but not limiting to upregulating or downregulating DNA, RNA, and protein 
TABlE 1: Summary of host-defense peptides discussed.

\begin{tabular}{|c|c|c|c|}
\hline $\begin{array}{l}\text { Peptide } \\
\text { name/inducers }\end{array}$ & Peptide sequence & $\begin{array}{l}\text { Current/potential } \\
\text { application in } \\
\text { urology }\end{array}$ & References \\
\hline $\begin{array}{l}\text { Lactoferrin-derived } \\
\text { peptide HLD1 }\end{array}$ & EATKCFQWQRNMRKVRGPPVSCIKR-NH2 & \multirow{2}{*}{$\begin{array}{l}\text { Oral } \\
\text { administration for } \\
\text { UTI }\end{array}$} & \multirow{2}{*}{ [17] } \\
\hline $\begin{array}{l}\text { Lactoferrin-derived } \\
\text { peptide HLD2 }\end{array}$ & TK@FQWQRNMRKVRGPPVS@IKR-NH2 & & \\
\hline Tachyplesin III & KWCFRVCYRGICYRKCR-NH2 & \multirow{5}{*}{$\begin{array}{l}\text { Antimicrobial } \\
\text { coating for } \\
\text { urologic devices }\end{array}$} & [7] \\
\hline Tet-20 & KRWRIRVRVIRKC-NH2 & & {$[18]$} \\
\hline RK1 (salt-tolerant) & RWKRWWRRKK & & {$[19]$} \\
\hline RK2 (salt-tolerant) & RKKRWWRRKK & & [19] \\
\hline Magainin II & GIGKFLHSAKKFGKAFVGEIMNS-NH2 & & {$[20-22]$} \\
\hline Cecropin A & KWKLFKKIEKVGQNIRDGIIKAGPAVAVVGQATQIAK-NH2 & \multirow{4}{*}{$\begin{array}{l}\text { Target bladder } \\
\text { cancer cells }\end{array}$} & \\
\hline Cecropin B & KWKVFKKIEKMGRNIRNGIVKAGPAIAVLGEAKAL-NH2 & & {$[23]$} \\
\hline Peptoids & $\begin{array}{l}\text { Most potent one analyzed: } \\
\text { H-(Nlys-Nspe-Nspe) } 4-\mathrm{NH} 2\end{array}$ & & {$[24]$} \\
\hline Human $\beta$-defensin-1 & DHYNCVSSGGQCLYSACPIFTKIQGTCYRGKAKCCK-NH2 & & {$[25-27]$} \\
\hline $\begin{array}{l}\text { OPN-derived } \\
\text { peptides }\end{array}$ & $\begin{array}{l}\text { Many OPN-derived peptides were analyzed; one of the more } \\
\text { promising ones being OPN-derived peptide D9: } \\
\text { ADAAADDAAADAAADDAA-NH2 }\end{array}$ & $\begin{array}{l}\text { Target kidney } \\
\text { stones }\end{array}$ & {$[28]$} \\
\hline
\end{tabular}

synthesis, altering gene expressions, enhancing neutrophil chemotaxis and function, promoting histamine release of mast cells, inhibiting tissue proteases, and stimulating wound healing $[7,8,12-14]$. The ability of these peptides to target multiple systems makes it difficult for bacteria to gain MDR against them, putting them at a great advantage compared to conventional antibiotics [4]. Because AMPs also stimulate the immune system in addition to being "antimicrobial," in 2006, it was suggested that these peptides should be named "host-defense peptides" rather than "antimicrobial peptides," where the latter name was given simply based on their initially discovered characteristic [12]. For this reason, these peptides will be referred to as "host-defense peptides" for the remaining of this review.

Host-defense peptides (HDPs) are typically 12 to 50 amino acids in length, are amphipathic with a net positive charge of +2 to +9 , and consist of a substantial portion of hydrophobic residues $(\geq 30 \%)[8,12,15]$. These properties allow the peptides to interact with bacterial membranes and insert and form pores; cationic portions of the peptide interact with the negatively charged surface of the bacterial outer membrane via electrostatic bonding [16]. Hydrophobic residues of the HDPs then allow them to be inserted into the lipid bilayer and permeabilize the membrane [16]. The exact mechanisms of how HDPs go beyond the bacterial membrane and affect other essential cellular activities, however, have yet to be discovered [13].

With the promising antimicrobial effects and host immune enhancements offered by HDPs, it is not surprising that they are now of high interest in the biomedical area. Here, we discuss the current and potential applications of these peptides in the field of urology, including urinary tract infections, urological devices, urologic cancers, and kidney stone disease. A summarizing table has been included to help the reader thoroughly understand the HDPs which will be discussed throughout this review (Table 1).

\section{Current and Potential Applications of Host-Defense Peptides in the Field of Urology}

2.1. Urinary Tract Infections. The urinary tract functions in close proximity with fecal microflora and the outside environment $[29,30]$. Yet, it must remain sterile to avoid disease $[29,30]$. Our body possesses several mechanisms to help clear the urinary tract of bacteria, including urine flow, changes in urine $\mathrm{pH}$, regular bladder emptying, chemicaldefense components of the uroepithelium, and, when stimulated with bacteria, epithelial shedding and influx of effector immune cells [29-31]. More recently discovered is the natural prevalence of HDPs released into our urine upon stimulation with bacteria [29, 30, 32]. When our body fails to keep the urinary tract sterile, bacterial infections may take place. Urinary tract infections (UTI) are one of the most common infections in humans, affecting predominantly females of any age [17].

Several HDPs of the urinary tract have been studied to determine their expression and function, including human beta-defensin-1 (hBD-1), cathelicidin, and ribonuclease 7 [29, $30,32]$. All three peptides are amongst a group of HDPs that are highly expressed by epithelial cells of the urinary tract upon stimulation with bacteria $[29,30,32]$. Although they are present in the urine of both healthy individuals and those with UTI, their level of expression significantly increases with acute pyelonephritis or cystitis, effectively revealing antibacterial activity at micromolar concentrations $[29,30,32]$. 
However, despite the regular release of HDPs into our urinary tract system by uroepithelial cells, it is apparent that the level of naturally produced HDPs may sometimes not be enough, hence giving rise to the frequent occurrence of UTI. Current therapies for UTI consist of antibiotics [17]. However, as previously mentioned, the high prevalence of MDR pathogens renders the treatment ineffective. Moreover, antibiotics have been associated with adverse effects, and they are often not recommended during pregnancy or in young children [17]. To overcome this predicament, Haversen et al. have examined the effectiveness of human HDP lactoferrin and lactoferrin-derived peptides, HLD1 (EATKCFQWQRNMRKVRGPPVSCIKR-NH2) and HLD2 (TK(C)FQWQRNMRKVRGPPVS(C)IKR-NH2) in clearing UTI when administered orally [17]. Lactoferrin possesses both antimicrobial and anti-inflammatory properties and is associated with host-defense at mucosal surfaces [17]. When orally administered to female mice $30 \mathrm{~min}$ after instillation of $10^{7}$ Escherichia coli colony forming units (CFU) into the urinary bladder, bacterial numbers in both the kidneys and the bladder were decreased to at least 1000-fold lower than that in control groups which received either phosphatebuffered saline or water when examined $24 \mathrm{~h}$ after inoculation [17]. Hence, oral administration of HDPs was shown to be sufficient in treating infection and inflammation at the urinary tract, possibly via renal secretion of the peptides to the site of infection [17]; it has been previously reported that lactoferrin often leaves the body of UTI patients via the urinary tract [33]. Other studies suggest that the molecule may remain intact throughout the gastrointestinal tract, allowing it to be absorbed into the blood under certain medical conditions [34]. Although the exact mechanism of action used by lactoferrin is far from being elucidated, this finding is extremely valuable as it suggests the potential use of orally administered peptides in place of conventional antibiotics. Using this protocol, other HDPs may also be tested to access their effectiveness towards targeting other remote sites of the body when taken orally.

Alternatively, instead of introducing external sources of HDPs into our system, the expression of peptides may be upregulated as a treatment for UTI; past findings have suggested the deficiency in natural HDP production to be one of the main factors leading to the development of certain infectious diseases as well as UTI [35]. This was confirmed by a recent study, where LL-37 levels were significantly lower in UTI patients after infection compared to uninfected individuals [36]. Hence, it has been suggested that induction of certain HDPs may be an effective treatment for UTI [35]. This was confirmed by Hertting et al.; when bladder biopsies were infected with uropathogenic $E$. coli, a significant increase in cathelicidin expression was induced using vitamin D [37]. Similarly, using a mouse model, Rivas-Santiago et al. were able to upregulate the expression of $\beta$-defensins 3 and 4 using L-isoleucine [38]. Other approaches include the use of butyrate and vitamin $\mathrm{D}$ to upregulate the expression of HDPs LL-37 and cathelicidin, respectively [39, 40].

Estrogen may also indirectly induce HDPs; postmenopausal women suffer from recurrent UTI frequently as a result of low levels of estrogen, leading to structural and chemical changes in the urogenital tract which increases the likelihood of contracting UTI [41]. When estrogen is locally supplemented, the improved integrity of the urinary tract is accompanied by an increased production of HDPs, including $\beta$-defensins $1-3$, cathelicidin, ribonuclease 7 , and psoriasin [41].

Indeed certain inducers are capable of upregulating the expression of various HDPs. This is important as many studies suggest the expression of particular peptides, such as $\beta$-defensins 3 and 14, to serve key roles in mucosal defense of the urinary tract, combating infections associated with the system [42].

2.2. Medical Devices. Catheter-associated urinary tract infections (CAUTI) are one of the most common sources of healthcare-associated infections, accounting for $80 \%$ of hospital-acquired infections worldwide [43]. In the United States alone, there are approximately 450,000 cases a year, and direct treatment amounts to over $\$ 350$ million annually [43, 44]. Upon insertion of the urinary catheter into the human body, bacteria adhere onto the surfaces of the implant [18, $19,43,45]$. Once adhered, they can grow and form colonies, eventually leading to a biofilm and causing infection and encrustation [7]. Biofilms are complex, multilayered communities of microorganisms adhered onto a surface and embedded in self-produced extracellular polymeric substances, which generally consist of extracellular DNA, proteins, and polysaccharides [45-47]. The extracellular matrix reduces the diffusion of antimicrobial compounds and the close proximity of the cells facilitates horizontal gene transfer between antibiotic-resistant and nonresistant bacterial strains, making them extremely resistant to antibiotic treatment $[45,48]$.

Since fully developed biofilms are difficult to treat, coating urinary catheters with antimicrobial compounds prior to implantation has been of high interest to prevent the formation of biofilms [43]. To date, several different types of coatings have been tested, including antibiotics, silver, triclosan, gendine, and heparin [43]. However, these compounds are often found to be cytotoxic, are associated with the development of antibiotic resistance, or are only effective in vitro and not in vivo $[19,43]$.

Recently, HDPs have been examined as a potential coating for urinary catheters and ureteral stents $[18,19$, 43]. Tachyplesin III (KWCFRVCYRGICYRKCR-NH2) is a HDP isolated from horseshoe crabs and has been shown to have broad spectrum activity [7]. Minardi et al. investigated the effect of coating Tachyplesin III on ureteral stents in preventing biofilm formation in vivo using a rat subcutaneous pouch model and found coated samples to inhibit bacterial growth up to 1000 times [7]. No drug related adverse effects were physically observed in any of the treated animals [7].

HDP implant coatings were further advanced when the use of polymer brushes was introduced $[18,19]$. By covalently grafting hydrophilic copolymer $(p o l y(\mathrm{~N}, \mathrm{~N}-\mathrm{dim}-$ ethylacrylamide) (PDMA) and poly(N-(3-aminopropyl) methacrylamide) (PAPMA)) chains onto a surface, and conjugating them to an optimized series of HDPs, Gao et al. were able to demonstrate the effective antimicrobial activity of a peptide-brush coating [18]. Polymer brush 
structures served as a flexible linker between HDPs and the surface while maximizing the density of peptides per coating [18]. In vitro, when $1-5 \times 10^{5} \mathrm{CFU} / \mathrm{mL}$ of Gram-positive or Gram-negative bacteria was introduced to titanium wires (Ti-wires) coated with peptide Tet-20 (KRWRIRVRVIRKC$\mathrm{NH} 2$ ), there was a 100,000-fold decrease in CFU for treated Ti-wires 4 hours after incubation in comparison to uncoated controls [18]. The activity was also demonstrated in vivo using a rat infection model; when coated and uncoated Ti-wires were implanted into subcutaneous pockets of the rat and were challenged with $10^{8} \mathrm{CFU}$ of Staphylococcus aureus under a 7-day implantation period, CFU was decreased by $85 \%$ for treated rats compared to controls [18]. Moreover, using scanning electron microscopy (SEM), modified 50\% haemolytic complement (CH50) analysis, and 3-(4,5-dimethylthiazol-2-yl)-2,5-diphenyltetrazolium bromide (MTT) assays, the authors were able to demonstrate that peptides gave insignificant platelet activation and adhesion, no complement activation in human blood, and were nontoxic to osteoblast-like cells, respectively [18]. All these results suggest HDPs to be a promising alternative to catheter coatings.

More recently, $\mathrm{Li}$ et al. demonstrated the effectiveness of another brush-peptide coating; they utilized allyl glycidyl ether (AGE) polymer brushes in place of PDMA/PAPMA brushes and novel peptides with salt-tolerant properties (engineered from C-terminus of salt-resistant human beta defensin 28) instead of Tet-20 [19]. These novel peptides were referred to as RK1 (RWKRWWRRKK-NH2) and RK2 (RKKRWWRRKK-NH2) [19]. The authors stated that many HDPs succumb to salt inactivation at physiological salt concentrations, and thus the HDPs must be tolerant to salt [19]. The particular brush-peptide coating was immobilized onto polydimethylsiloxane and urinary catheter surfaces and was introduced to E. coli, S. aureus, and Candida albicans [19]. In vitro assays showed coated slides exhibited $>70 \%$ killing activity towards all pathogens tested, with almost $100 \%$ inhibition of microbial colonization to surfaces [19]. Additionally, no toxicity towards smooth muscle cells was observed, as demonstrated using the MTT assay [19].

Indeed, brush-peptide coatings may be the next golden coating for urinary catheters to help prevent biofilm formation and infection. However, more clinically relevant in vivo models must be used to further test these coatings before they can be made available to the public.

2.3. Cancer. Besides taking a role in UTI and urologic devices, HDPs also serve a prominent role in a disease which affects 14.1 million adults per year worldwide and results in 8.2 million deaths annually: cancer [49]. In this section, we discuss the use of HDPs in bladder cancer, prostate cancer, and kidney cancer.

2.3.1. Bladder Cancer. Each year, approximately 75,000 new cases of bladder cancer are diagnosed, with $20 \%$ of them leading to death [50]. If treated by transurethral resection alone, recurrence and progressiveness of nonmuscle invasive bladder cancers can occur in $80 \%$ of the cases [20]. Various chemotherapeutic drugs have been established for treatment, including postoperative adjuvant intravesicle instillations of mitomycin, epirubicin, doxorubicin, and immunotherapy with Bacillus Calmette-Guérin (BCG) [23, 51, 52]. However, current treatments have been disappointing with respect to long-term outcomes and, due to their lack of specificity, are often associated with many side effects; $38.8 \%$ of patients treated with BCG and $46.4 \%$ of patients treated with mitomycin $\mathrm{C}$ developed tumor recurrences within 2 years after treatment $[24,53]$. BCG is also associated with moderate to severe side effects, including arthritis, febrile episodes, and risk of sepsis $[23,54,55]$. It is also common for patients to develop multidrug resistance, rendering multiple chemotherapeutics ineffective [56]. Thus, it is important to search for alternative treatments.

Interestingly, although the use of HDPs has mainly been used to target pathogens, the peptides, particularly with magainin II (GIGKFLHSAKKFGKAFVGEIMNS-NH2), have recently been reported to have significant cytotoxic effect against a wide range of cancer cell lines, including breast and lung cancers, melanoma, lymphomas, and leukemias [20$22,57,58]$. Lehmann et al. were particularly interested in evaluating the activity of magainin II, a peptide originally isolated from the skin of African frog Xenopus laevis, against bladder cancer cells [20]. Using water soluble 2-(4-iodophenyl)-3-(4nitrophenyl)-5-(2,4-disulfophenyl)-2H-tetra-zolium (WST1), bromodeoxyuridine (BrdU), and lactate dehydrogenase (LDH) assays, the authors tested antitumor activity of the HDP against 3 different bladder cell lines as well as 2 benign fibroblast cell lines as noncancerous controls [20]. Magainin II significantly inhibited both cell proliferation and DNA synthesis in all bladder cancer cells tested while having no effect on the fibroblast cell lines, demonstrating the specificity of the peptide towards cancer cell lines [20]. Potent concentrations of magainin II for tumor cells were significantly lower than that required to damage normal fibroblasts, erythrocytes, and peripheral blood lymphocytes [59]. The peptide was also shown to be highly resistant against serum proteolysis [60]. In another study using an in vivo severe combined immunodeficiency mouse model, introduction of magainins and their analogues to melanoma cells leads to a complete tumor regression [22]. When administered intraperitoneally to mice with ascites tumors, magainin analogues were also able to increase the rodents' survival time [21].

With magainin II looking promising, other studies looked into other HDPs that may also give similar antitumor effects [23]. One HDP family with structural and functional similarity to magainin II was the cecropin family, first isolated from the giant silk moth, Hyalophora cecropia [23]. Cecropins have been previously demonstrated to possess specific anticancer activity against small cell lung cancer, mammalian leukemia, gastric cancer cells, and lymphoma and colon carcinoma cell lines [61]. Using the same tests performed to evaluate the tumoricidal activity of magainin II, Lehmann and his colleagues evaluated the potency of cecropin A (KWKLFKKIEKVGQNIRDGIIKAGPAVAVVGQATQIAK-NH2) and cecropin B (KWKVFKKIEKMGRNIRNGIVKAGPAIAVLGEAKAL-NH2) against bladder cancer cells [23]. Similar to magainin II, cecropins were selective for cancer cell lines, sparing all benign cells [23]. Inhibition of cell viability and 
proliferation was observed at a dose-dependent manner [23]. Scanning electron microscopy allowed visualization of lethal membrane disruption in all bladder cancer cells tested, which was not present in control cells [23]. Moreover, transfection of human bladder tumor cells with cecropin genes has been shown to reduce tumor sizes in nude mouse models [62]. Cecropins have also been shown to be largely resistant against serum and urine proteolysis, giving them an advantage over classic chemotherapeutic agents such as mitomycin, which is highly unstable in urine [63].

Although both magainin and cecropins seem to be promising, some reports have suggested making synthetic modifications to further optimize their bioactivity and rate of biodegradation $[24,64]$; Huang et al. worked to bypass potential proteolytic sensitivity by using nonnatural peptidomimetics [24]. They developed poly-N-substituted glycines (peptoids), which mimic the cationic, amphipathic structural feature of magainin II but consist of slight molecular changes, ensuring them to be protease-resistant and more stable [24]. Based on 3-(4,5-dimethylthiazol-2-yl)5-(3-carboxy-methoxyphenyl)-2-(4-sulfophenyl)-2H-tetrazolium, inner salt (MTS) assays, the peptoids exhibited fast, potent cytotoxicity at low micromolar concentrations against a wide range of human cancer cell lines, with increased cytotoxicity when treatment duration was longer [24]. When subjected to primary dermal fibroblasts and red blood cells, the peptides showed minimal influence, validating their selectivity for cancer cells [24]. Looking into structureactivity correlations, hydrophobicity and amphipathicity seem to be important for the tumoricidal activity, with peptoid chains of approximately 13 residues having highest potency. The efficacy of peptoids in vivo has been validated using a clinically relevant orthotopic xenotransplantation model, where human breast cancer cells were implanted into immunocompromised mice [24]. When peptoid was injected 2 weeks after implantation, tumor growth was significantly inhibited [24].

Although some HDPs appear to have significant specific tumoricidal activity against cancer cell lines, the cytotoxic mechanisms remain to be discovered [23]. The mechanism behind the ability of these peptides to selectively target cancer cells while leaving benign cells spared also remains to be mapped [23]. A possibility may be due to physiochemical differences in the target cell membranes, such as differences in lipoprotein content or fluidity [23]. However, their high selectivity and tumoricidal capabilities may allow for optimal therapy in vivo at low therapeutic concentrations, potentially limiting any side effects associated with them [23]. It is also important to point out that the antitumor effect appears to be unaffected by the multidrug resistant cells, which is a common phenotype observed in cancer cells $[23,24]$. Such advantages may allow these HDPs to be used as treatments for bladder cancer patients in the near future.

2.3.2. Prostate/Kidney Cancer. Prostate cancer is the second most common cause of death in the United States, and approximately 1 of every 6 men will get diagnosed with the deadly disease during their lifetime [50]. Kidney cancer is not fatal, but with approximately 65,000 new cases a year and $20 \%$ of those resulting in death, it still presents a major concern to public health [50]. Although the two types of cancers affect different parts of the urinary tract, one of the similar characteristics between them involves the loss of human $\beta$-defensin1 (DHYNCVSSGGQCLYSACPIFTKIQGTCYRGKAKCCKNH2) [25].

Human $\beta$-defensin-1 (hBD-1) has been known as a HDP of the urogenital tissues for approximately two decades [32]. However, it was only within the past 10 years when the peptide started gaining extensive attention in its role as an anticancer agent [25-27, 65]. By performing immunohistochemical analysis for hBD-1 in clinical specimens of both prostate cancer and renal cell carcinoma, Donald et al. found significant cancer-specific downregulation of the peptide in $82 \%$ and $90 \%$ of prostate cancer and renal cell carcinomas, respectively, while adjacent benign regions were unaffected [25]. Based on the authors' analysis on promoter polymorphisms, it was suggested that hBD-1 acts as a tumor suppressor, promoting caspase-3-mediated apoptosis of prostate and renal cancer cells when overexpressed [26, 27]. hBD-1 is located in chromosome 8 at segment region 8 p23.2, a region where multiple tumor suppressor genes reside and genetic alternations are common in prostate and renal carcinoma $[26,27]$.

To gain insight into how hBD-1 may affect the behavior of cancer cells, Bullard et al. cloned the peptide and expressed it ectopically in different prostate cancer cell lines, including DU145, PC3, and LNCap [27]. Introduction of the peptide showed cytotoxic effects against DU145 and PC3, but not LNCap, which suggests hBD-1 targets mainly late-stage prostate carcinoma cells [27]. As such, with the specificity against prostate and renal cancer cells and its tumor-suppressive activity, hBD-1 may be used as an effective anticancer agent [27]. It may be interesting to see what may happen when hBD-1 inducers, such as the ones mentioned in Section 2.1 of this review article, are introduced to the cancer cell lines.

2.4. Kidney Stone Disease. Kidney stone disease is a common pathological disorder in industrialized countries and affects $10-15 \%$ of men and $3-5 \%$ of women in the United States, with prevalence on the rise $[66,67]$. The disease causes significant morbidities, and adverse effects are often experienced when the stones reach an appreciable size, which can become dislodged from the epithelial membrane [28]. Current treatments are limited to increased water intake, supervised dieting, and alkalinization agents $[28,68]$. Although such treatments can provide temporary relief, they do not lower the incidence of stone formation [69].

Kidney stones can consist of different types of components, but the main component is calcium oxalate, which comprises 70\% of kidney stones [70]. Two polymorphs of calcium oxalate can form, one being the monohydrate (COM) and the other being dihydrate (COD) [71]. COM is the most abundant phase in stone formers and typically constitutes the core of kidney stones [72]. They are rarely excreted via the urine by healthy individuals [70]. COD on the other hand is excreted regularly by both healthy individuals and stone formers [70]. They are less adherent and less stable and cause less damage to cell membrane compared to $\operatorname{COM}[28,70,73]$. 


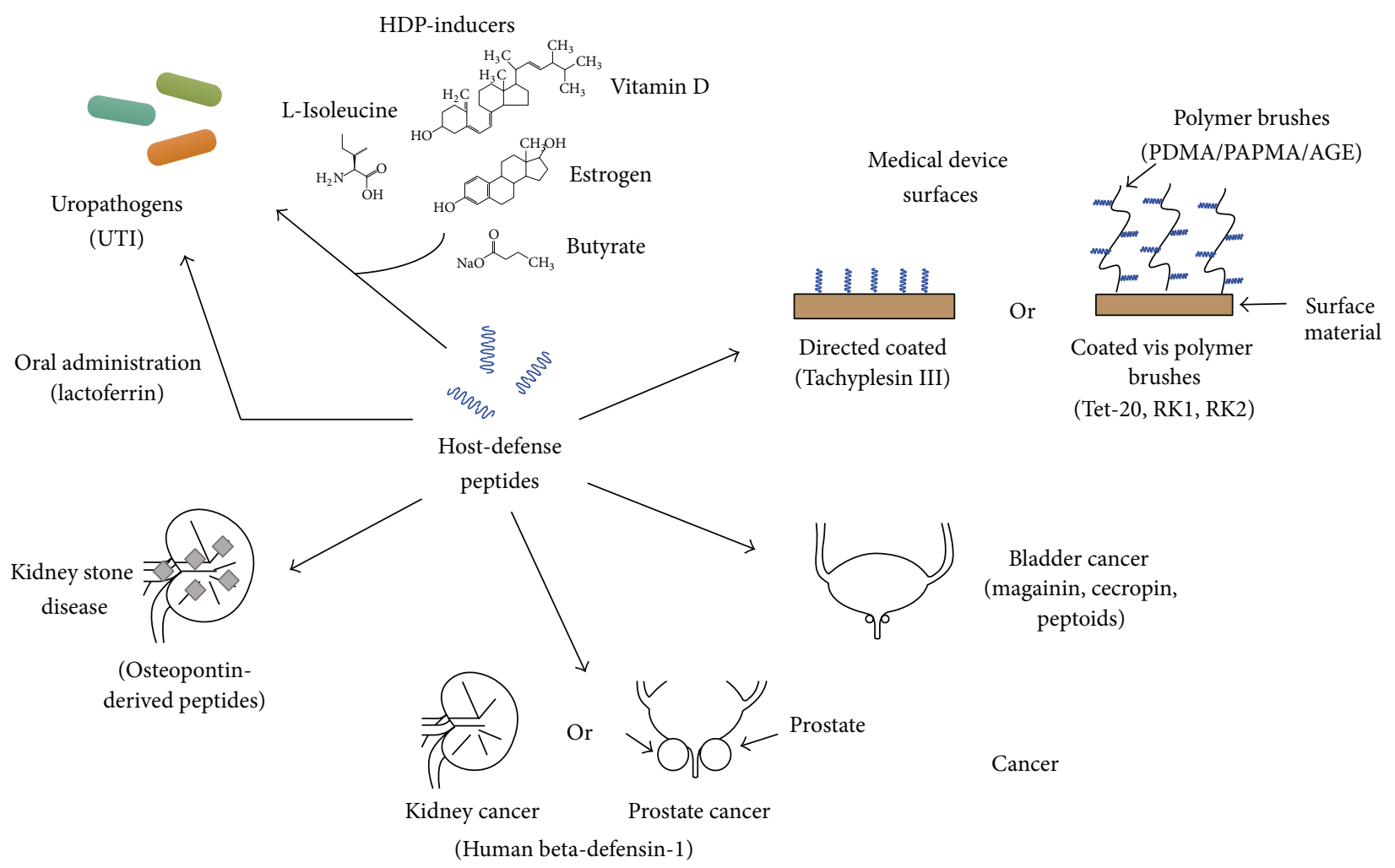

FIGURE 1: Applications of host-defense peptides in the field of urology.

By preventing the dissolution of COD to COM, crystal deposition and kidney stone formation may be suppressed [73].

The inhibition of COM formation and initiation of COD polymorph has been demonstrated by osteopontin (OPN), which are highly acidic or hydrophilic peptides [70]. Although it is not consistent with the typical cationic and hydrophobic properties that define HDPs, OPN has been reported to play crucial roles as an immune modulator, being involved with chemotactic properties to recruit cells to inflammatory sites, with mediating cell activation and cytokine production and with wound healing $[12,74,75]$. As such, for this review, we consider it as a member of HDP.

OPN-derived peptides have been shown to be effective in inhibiting COM formation while promoting COD precipitation, with the main active properties being the considerable portion of aspartic acid-rich regions, motifs, phosphorylated peptides, hydrophilic residues, net negative charges, and peptide length $[28,70,76]$. Some of the most potent OPN-derived peptides have been shown to be capable of reducing COM growth by more than $90 \%$ [77]. Farmanesh et al. have recently focused on designing and screening short peptides with functional moieties made to mimic COM inhibitors [28]. Different peptide sequences were tested to determine the difference in anti-COM activity when alanine and aspartic acid amino acids were arranged differently [28]. The authors found that subtle alterations in the sequence of the acidic residues had profound effects on the anti-COM potential [28]. By using high-throughput in situ calcium ion-selective electrode (ISE) screening to rapidly and reproducibly screen large peptide libraries, peptide sequences were discovered which inhibited COM formation more effectively than wellknown COM inhibitors, such as citrate [28]. With bulk crystallization which involved optical and scanning electron microscopy, effective inhibitors were validated and were found to have a high tendency to shift for morphology of COM crystals from hexagonal morphology to diamondshaped platelets, possibly due to the preferential binding of peptides to particular faces of the COM [28]. Effective COMinhibiting peptides were also found to reduce the growth rates of COM [28]. These particular results suggest these anti$\mathrm{COM}$ peptides may be valuable candidates as future therapies for kidney stone formers.

Table 1 and Figure 1 have been included to aid in understanding the characteristic of HDPs discussed in this review, as well as their current and potential applications in the field of urology (Table 1, Figure 1).

\section{Conclusions}

As shown in this review, the wide-ranging functionality of HDPs against infection and disease of the urinary tract expands the peptides' activity list to well beyond the "antimicrobial peptide" originally assigned to them. From targeting bacteria and cancer cells to preventing kidney stone formation, no single peptide carried all the different traits necessary to fully treat each condition. Within urology, many potential applications of HDPs have been studied, with very promising results observed. Given that these HDPs do not appear to be susceptible to MDR bacteria and cancer cells, they may 
potentially form the compounds of the next "golden age" of new antimicrobials in the near future. However, before they reach that stage, further studies are required to thoroughly understand their advantages, limitations, and mechanisms of action.

\section{Conflict of Interests}

The authors declare that there is no conflict of interests regarding the publication of this paper.

\section{Authors' Contribution}

Each author has contributed to the research of this review article and drafting and finalizing this paper.

\section{References}

[1] G. F. Gibberd, " Prontosil etc. in puerperal Streptococcus infections," British Medical Journal, vol. 2, no. 4005, pp. 695698, 1937.

[2] J. Davies and D. Davies, "Origins and evolution of antibiotic resistance," Microbiology and Molecular Biology Reviews, vol. 74, no. 3, pp. 417-433, 2010.

[3] B. Spellberg, R. Guidos, D. Gilbert et al., "The epidemic of antibiotic-resistant infections: a call to action for the medical community from the infectious diseases society of America," Clinical Infectious Diseases, vol. 46, no. 2, pp. 155-164, 2008.

[4] S. R. Dennison, F. Harris, M. Mura, L. H. G. Morton, A. Zvelindovsky, and D. A. Phoenix, "A novel form of bacterial resistance to the action of eukaryotic host defense peptides, the use of a lipid receptor," Biochemistry, vol. 52, no. 35, pp. 6021$6029,2013$.

[5] D. A. Tadesse, S. Zhao, E. Tong et al., "Antimicrobial drug resistance in Escherichia coli from humans and food animals, United States, 1950-2002," Emerging Infectious Diseases, vol. 18, no. 5, pp. 741-749, 2012.

[6] I. M. Cullen, R. P. Manecksha, E. McCullagh et al., "The changing pattern of antimicrobial resistance within 42033 Escherichia coli isolates from nosocomial, community and urology patient-specific urinary tract infections, Dublin, 19992009," BJU International, vol. 109, no. 8, pp. 1198-1206, 2012.

[7] D. Minardi, R. Ghiselli, O. Cirioni et al., "The antimicrobial peptide Tachyplesin III coated alone and in combination with intraperitoneal piperacillin-tazobactam prevents ureteral stent Pseudomonas infection in a rat subcutaneous pouch model," Peptides, vol. 28, no. 12, pp. 2293-2298, 2007.

[8] R. E. Hancock, "Cationic peptides: effectors in innate immunity and novel antimicrobials," The Lancet Infectious Diseases, vol. 1, no. 3, pp. 156-164, 2001.

[9] C. D. Fjell, J. A. Hiss, R. E. W. Hancock, and G. Schneider, "Designing antimicrobial peptides: form follows function," Nature Reviews Drug Discovery, vol. 11, no. 1, pp. 37-51, 2012.

[10] M. L. Mangoni, "Host-defense peptides: from biology to therapeutic strategies," Cellular and Molecular Life Sciences, vol. 68, no. 13, pp. 2157-2159, 2011.

[11] S. A. Baltzer and M. H. Brown, "Antimicrobial peptidespromising alternatives to conventional antibiotics," Journal of Molecular Microbiology and Biotechnology, vol. 20, no. 4, pp. 228-235, 2011.
[12] R. E. Hancock and H.-G. Sahl, "Antimicrobial and host-defense peptides as new anti-infective therapeutic strategies," Nature Biotechnology, vol. 24, no. 12, pp. 1551-1557, 2006.

[13] R. L. Williams, H. Y. Sroussi, K. Leung, and P. T. Marucha, "Antimicrobial decapeptide KSL-W enhances neutrophil chemotaxis and function," Peptides, vol. 33, no. 1, pp. 1-8, 2012.

[14] A. S. Ali, C. L. Townes, J. Hall, and R. S. Pickard, "Maintaining a sterile urinary tract: the role of antimicrobial peptides," The Journal of Urology, vol. 182, no. 1, pp. 21-28, 2009.

[15] A. K. Marr, W. J. Gooderham, and R. E. Hancock, "Antibacterial peptides for therapeutic use: obstacles and realistic outlook," Current Opinion in Pharmacology, vol. 6, no. 5, pp. 468-472, 2006.

[16] K. A. Brogden, "Antimicrobial peptides: pore formers or metabolic inhibitors in bacteria?" Nature Reviews Microbiology, vol. 3, no. 3, pp. 238-250, 2005.

[17] L. A. Haversen, I. Engberg, L. Baltzer, G. Dolphin, L. A. Hanson, and I. Mattsby-Baltzer, "Human lactoferrin and peptides derived from a surface-exposed helical region reduce experimental Escherichia coli urinary tract infection in mice," Infection and Immunity, vol. 68, no. 10, pp. 5816-5823, 2000.

[18] G. Gao, D. Lange, K. Hilpert et al., “The biocompatibility and biofilm resistance of implant coatings based on hydrophilic polymer brushes conjugated with antimicrobial peptides," Biomaterials, vol. 32, no. 16, pp. 3899-3909, 2011.

[19] X. Li, P. Li, R. Saravanan et al., "Antimicrobial functionalization of silicone surfaces with engineered short peptides having broad spectrum antimicrobial and salt-resistant properties," Acta Biomaterialia, vol. 10, no. 1, pp. 258-266, 2014.

[20] J. Lehmann, M. Retz, S. S. Sidhu et al., "Antitumor activity of the antimicrobial peptide magainin II against bladder cancer cell lines," European Urology, vol. 50, no. 1, pp. 141-147, 2006.

[21] M. A. Baker, W. L. Maloy, M. Zasloff, and L. S. Jacob, "Anticancer efficacy of Magainin2 and analogue peptides," Cancer Research, vol. 53, no. 13, pp. 3052-3057, 1993.

[22] P. W. Soballe, W. L. Maloy, M. L. Myrga, L. S. Jacob, and M. Herlyn, "Experimental local therapy of human-melanoma with lytic magainin peptides," International Journal of Cancer, vol. 60, no. 2, pp. 280-284, 1995.

[23] H. Suttmann, M. Retz, F. Paulsen et al., "Antimicrobial peptides of the Cecropin-family show potent antitumor activity against bladder cancer cells," BMC Urology, vol. 8, article 5, 2008.

[24] W. Huang, J. Seo, S. B. Willingham et al., "Learning from hostdefense peptides: cationic, amphipathic peptoids with potent anticancer activity," PLoS ONE, vol. 9, no. 2, Article ID e90397, 2014.

[25] C. D. Donald, C. Q. Sun, S. D. Lim et al., "Cancer-specific loss of beta-defensin 1 in renal and prostatic carcinomas," Laboratory Investigation, vol. 83, no. 4, pp. 501-505, 2003.

[26] C. Q. Sun, R. Arnold, C. Fernandez-Golarz et al., "Human $\beta$-defensin-1, a potential chromosome $8 \mathrm{p}$ tumor suppressor: control of transcription and induction of apoptosis in renal cell carcinoma," Cancer Research, vol. 66, no. 17, pp. 8542-8549, 2006.

[27] R. S. Bullard, W. Gibson, S. K. Bose et al., "Functional analysis of the host defense peptide Human Beta Defensin-1: new insight into its potential role in cancer," Molecular Immunology, vol. 45, no. 3, pp. 839-848, 2008.

[28] S. Farmanesh, J. Chung, D. Chandra, R. D. Sosa, P. Karande, and J. D. Rimer, "High-throughput platform for design and screening of peptides as inhibitors of calcium oxalate monohydrate 
crystallization," Journal of Crystal Growth, vol. 373, pp. 13-19, 2013.

[29] M. Chromek, Z. Slamová, P. Bergman et al., "The antimicrobial peptide cathelicidin protects the urinary tract against invasive bacterial infection," Nature Medicine, vol. 12, no. 6, pp. 636-641, 2006.

[30] J. D. Spencer, A. L. Schwaderer, H. Wang et al., "Ribonuclease 7 , an antimicrobial peptide upregulated during infection, contributes to microbial defense of the human urinary tract," Kidney International, vol. 83, no. 4, pp. 615-625, 2013.

[31] T. Weichhart, M. Haidinger, W. H. Hörl, and M. D. Säemann, "Current concepts of molecular defence mechanisms operative during urinary tract infection," European Journal of Clinical Investigation, vol. 38, supplement 2, pp. 29-38, 2008.

[32] E. V. Valore, C. H. Park, A. J. Quayle, K. R. Wiles, P. B. McCray Jr., and T. Ganz, "Human $\beta$-defensin-1: an antimicrobial peptide of urogenital tissues," The Journal of Clinical Investigation, vol. 101, no. 8, pp. 1633-1642, 1998.

[33] Y. Pan, G. A. Sonn, M. L. Y. Sin et al., "Electrochemical immunosensor detection of urinary lactoferrin in clinical samples for urinary tract infection diagnosis," Biosensors and Bioelectronics, vol. 26, no. 2, pp. 649-654, 2010.

[34] D. Legrand, E. Elass, A. Pierce, and J. Mazurier, "Lactoferrin and host defence: an overview of its immuno-modulating and antiinflammatory properties," BioMetals, vol. 17, no. 3, pp. 225-229, 2004.

[35] B. Rivas-Santiago, C. J. Serrano, and J. A. Enciso-Moreno, "Susceptibility to infectious diseases based on antimicrobial peptide production," Infection and Immunity, vol. 77, no. 11, pp. 4690-4695, 2009.

[36] K. L. Nielsen, P. Dynesen, P. Larsen, L. Jakobsen, P. S. Andersen, and N. Frimodt-Møller, "Role of urinary cathelicidin LL-37 and human $\beta$-defensin 1 in uncomplicated escherichia coli urinary tract infections," Infection and Immunity, vol. 82, no. 4, pp. 15721578, 2014.

[37] O. Hertting, Å. Holm, P. Lüthje et al., "Vitamin D induction of the human antimicrobial peptide cathelicidin in the urinary bladder," PLoS ONE, vol. 5, no. 12, Article ID e15580, 2010.

[38] C. E. Rivas-Santiago, B. Rivas-Santiago, D. A. León, J. Castañeda-Delgado, and R. Hernández Pando, "Induction of $\beta$-defensins by l-isoleucine as novel immunotherapy in experimental murine tuberculosis," Clinical and Experimental Immunology, vol. 164, no. 1, pp. 80-89, 2011.

[39] M. Schwab, V. Reynders, Y. Shastri, S. Loitsch, J. Stein, and O. Schröder, "Role of nuclear hormone receptors in butyratemediated up-regulation of the antimicrobial peptide cathelicidin in epithelial colorectal cells," Molecular immunology, vol. 44, no. 8, pp. 2107-2114, 2007.

[40] J. Schauber, R. A. Dorschner, A. B. Coda et al., "Injury enhances TLR2 function and antimicrobial peptide expression through a vitamin D-dependent mechanism," The Journal of Clinical Investigation, vol. 117, no. 3, pp. 803-811, 2007.

[41] P. Lüthje, A. Lindén Hirschberg, and A. Brauner, "Estrogenic action on innate defense mechanisms in the urinary tract," Maturitas, vol. 77, no. 1, pp. 32-36, 2014.

[42] B. Becknell, J. D. Spencer, A. R. Carpenter et al., "Expression and antimicrobial function of beta-defensin 1 in the lower urinary tract," PLoS ONE, vol. 8, no. 10, Article ID e77714, 2013.

[43] J. Lo, D. Lange, and B. Chew, "Ureteral stents and foley catheters-associated urinary tract infections: the role of coatings and materials in infection prevention," Antibiotics, vol. 3 , no. 1 , pp. 87-97, 2014.
[44] P. J. Nowatzki, R. R. Koepsel, P. Stoodley et al., "Salicylic acid-releasing polyurethane acrylate polymers as anti-biofilm urological catheter coatings," Acta Biomaterialia, vol. 8, no. 5, pp. 1869-1880, 2012.

[45] F. L. Brancatisano, G. Maisetta, M. Di Luca et al., "Inhibitory effect of the human liver-derived antimicrobial peptide hepcidin 20 on biofilms of polysaccharide intercellular adhesin (PIA)-positive and PIA-negative strains of Staphylococcus epidermidis," Biofouling, vol. 30, no. 4, pp. 435-446, 2014.

[46] J. W. Costerton, P. S. Stewart, and E. P. Greenberg, "Bacterial biofilms: a common cause of persistent infections," Science, vol. 284, no. 5418, pp. 1318-1322, 1999.

[47] N. Høiby, T. Bjarnsholt, M. Givskov, S. Molin, and O. Ciofu, "Antibiotic resistance of bacterial biofilms," International Journal of Antimicrobial Agents, vol. 35, no. 4, pp. 322-332, 2010.

[48] N. Hoiby, O. Ciofu, H. K. Johansen et al., "The clinical impact of bacterial biofilms," International Journal of Oral Science, vol. 3, no. 2, pp. 55-65, 2011.

[49] “Cancer research UK," Nature Cell Biology, vol. 4, no. 3, article E45, 2002.

[50] R. Siegel, J. Ma, Z. Zou, and A. Jemal, "Cancer statistics, 2014," CA: A Cancer Journal for Clinicians, vol. 64, no. 1, pp. 9-29, 2014.

[51] W. Oosterlinck, B. Lobel, G. Jakse, P.-U. Malmström, M. Stöckle, and C. Sternberg, "Guidelines on bladder cancer," European Urology, vol. 41, no. 2, pp. 105-112, 2002.

[52] A. Stenzl, N. C. Cowan, M. de Santis et al., "Treatment of muscle-invasive and metastatic bladder cancer: update of the EAU guidelines," European Urology, vol. 59, no. 6, pp. 1009-1018, 2011.

[53] A. Böhle, D. Jocham, and P. R. Bock, "Intravesical bacillus Calmette-Guerin versus mitomycin $\mathrm{C}$ for superficial bladder cancer: a formal meta-analysis of comparative studies on recurrence and toxicity," The Journal of Urology, vol. 169, no. 1, pp. 90-95, 2003.

[54] M. Brausi, J. Oddens, R. Sylvester et al., "Side effects of bacillus calmette-guérin (BCG) in the treatment of intermediate- and high-risk Ta, T1 papillary carcinoma of the bladder: results of the EORTC genito-urinary cancers group randomised phase 3 study comparing one-third dose with full dose and 1 year with 3 years of maintenance BCG," European Urology, vol. 65, no. 1, pp. 69-76, 2014.

[55] A. P. M. van der Meijden, M. Brausi, V. Zambon et al., "Intravesical instillation of epirubicin, bacillus Calmette-Guerin and bacillus Calmette-Guerin plus isoniazid for intermediate and high risk TA, T1 papillary carcinoma of the bladder: a European Organization for Research and Treatment of Cancer GenitoUrinary Group randomized phase III trial," The Journal of Urology, vol. 166, no. 2, pp. 476-481, 2001.

[56] J. I. Fletcher, M. Haber, M. J. Henderson, and M. D. Norris, "ABC transporters in cancer: more than just drug efflux pumps," Nature Reviews Cancer, vol. 10, no. 2, pp. 147-156, 2010.

[57] R. A. Cruciani, J. L. Barker, M. Zasloff, H.-C. Chen, and O. Colamonici, "Antibiotic magainins exert cytolytic activity against transformed cell lines through channel formation," Proceedings of the National Academy of Sciences of the United States of America, vol. 88, no. 9, pp. 3792-3796, 1991.

[58] Y. Ohsaki, A. F. Gazdar, H.-C. Chen, and B. E. Johnson, "Antitumor activity of magainin analogues against human lung cancer cell lines," Cancer Research, vol. 52, no. 13, pp. 3534-3538, 1992. 
[59] W. L. Maloy and U. P. Kari, "Structure-activity studies on magainins and other host defense peptides," Biopolymers, vol. 37, no. 2, pp. 105-122, 1995.

[60] R. Bessalle, A. Kapitkovsky, A. Gorea, I. Shalit, and M. Fridkin, "All-D-magainin: chirality, antimicrobial activity and proteolytic resistance," FEBS Letters, vol. 274, no. 1-2, pp. 151-155, 1990.

[61] R. J. Boohaker, M. W. Lee, P. Vishnubhotla, J. M. Perez, and A. R. Khaled, "The use of therapeutic peptides to target and to kill cancer cells," Current Medicinal Chemistry, vol. 19, no. 22, pp. 3794-3804, 2012.

[62] D. Winder, W. H. Günzburg, V. Erfle, and B. Salmons, "Expression of antimicrobial peptides has an antitumour effect in human cells," Biochemical and Biophysical Research Communications, vol. 242, no. 3, pp. 608-612, 1998.

[63] H. G. Boman, "Antibacterial peptides: basic facts and emerging concepts," Journal of Internal Medicine, vol. 254, no. 3, pp. 197215, 2003.

[64] N. P. Chongsiriwatana, J. A. Patch, A. M. Czyzewski et al., "Peptoids that mimic the structure, function, and mechanism of helical antimicrobial peptides," Proceedings of the National Academy of Sciences of the United States of America, vol. 105, no. 8, pp. 2794-2799, 2008.

[65] N. Droin, J.-B. Hendra, P. Ducoroy, and E. Solary, "Human defensins as cancer biomarkers and antitumour molecules," Journal of Proteomics, vol. 72, no. 6, pp. 918-927, 2009.

[66] J. Tang, P. Mettler, K. Mcfann, and M. Chonchol, “The association of prevalent kidney stone disease with mortality in US adults: the national health and nutrition examination survey III, 1988-1994," American Journal of Nephrology, vol. 37, no. 5, pp. 501-506, 2013.

[67] K. K. Stamatelou, M. E. Francis, C. A. Jones, L. M. Nyberg Jr., and G. C. Curhan, "Time trends in reported prevalence of kidney stones in the United States: 1976-1994," Kidney International, vol. 63, no. 5, pp. 1817-1823, 2003.

[68] A. D. Rule, A. E. Krambeck, and J. C. Lieske, "Chronic kidney disease in kidney stone formers," Clinical Journal of the American Society of Nephrology, vol. 6, no. 8, pp. 2069-2075, 2011.

[69] F. L. Coe and J. R. Asplin, "Stopping the stones," Science, vol. 330, no. 6002, pp. 325-326, 2010.

[70] B. P. H. Chan, K. Vincent, G. A. Lajoie, H. A. Goldberg, B. Grohe, and G. K. Hunter, "On the catalysis of calcium oxalate dihydrate formation by osteopontin peptides," Colloids and Surfaces B: Biointerfaces, vol. 96, pp. 22-28, 2012.

[71] J. C. Lieske and F. G. Toback, "Renal cell-urinary crystal interactions," Current Opinion in Nephrology and Hypertension, vol. 9, no. 4, pp. 349-355, 2000.

[72] N. S. Mandel and G. S. Mandel, "Urinary tract stone disease in the United States veteran population. II. Geographical analysis of variations in composition," Journal of Urology, vol. 142, no. 6, pp. 1516-1521, 1989.

[73] B. B. Tomazic and G. H. Nancollas, "The kinetics of dissolution of calcium oxalate hydrates. II. The dihydrate," Investigative Urology, vol. 18, no. 2, pp. 97-101, 1980.

[74] D. T. Denhardt, M. Noda, A. W. O’Regan, D. Pavlin, and J. S. Berman, "Osteopontin as a means to cope with environmental insults: regulation of inflammation, tissue remodeling, and cell survival," The Journal of Clinical Investigation, vol. 107, no. 9, pp. 1055-1061, 2001.
[75] T. Uede, Y. Katagiri, J. Iizuka, and M. Murakami, "Osteopontin, a coordinator of host defense system: a cytokine or an extracellular adhesive protein?" Microbiology and Immunology, vol. 41, no. 9, pp. 641-648, 1997.

[76] K. Singh, D. Deonarine, V. Shanmugam et al., "Calciumbinding properties of osteopontin derived from non-osteogenic sources," Journal of Biochemistry, vol. 114, no. 5, pp. 702-707, 1993.

[77] T. Jung, X. Sheng, C. K. Choi, W.-S. Kim, J. A. Wesson, and M. D. Ward, "Probing crystallization of calcium oxalate monohydrate and the role of macromolecule additives with in situ atomic force microscopy," Langmuir, vol. 20, no. 20, pp. 8587-8596, 2004. 

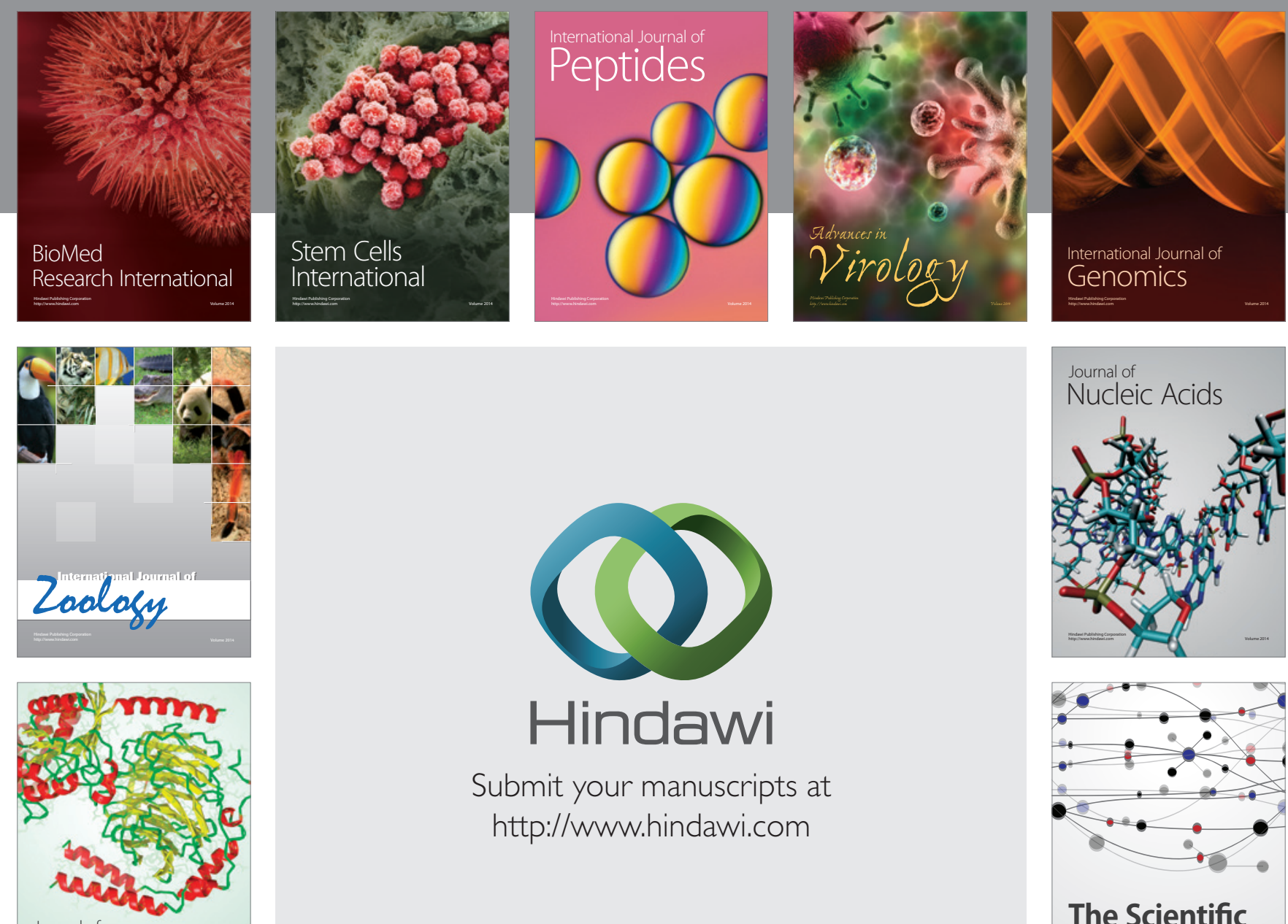

Submit your manuscripts at

http://www.hindawi.com

Journal of
Signal Transduction
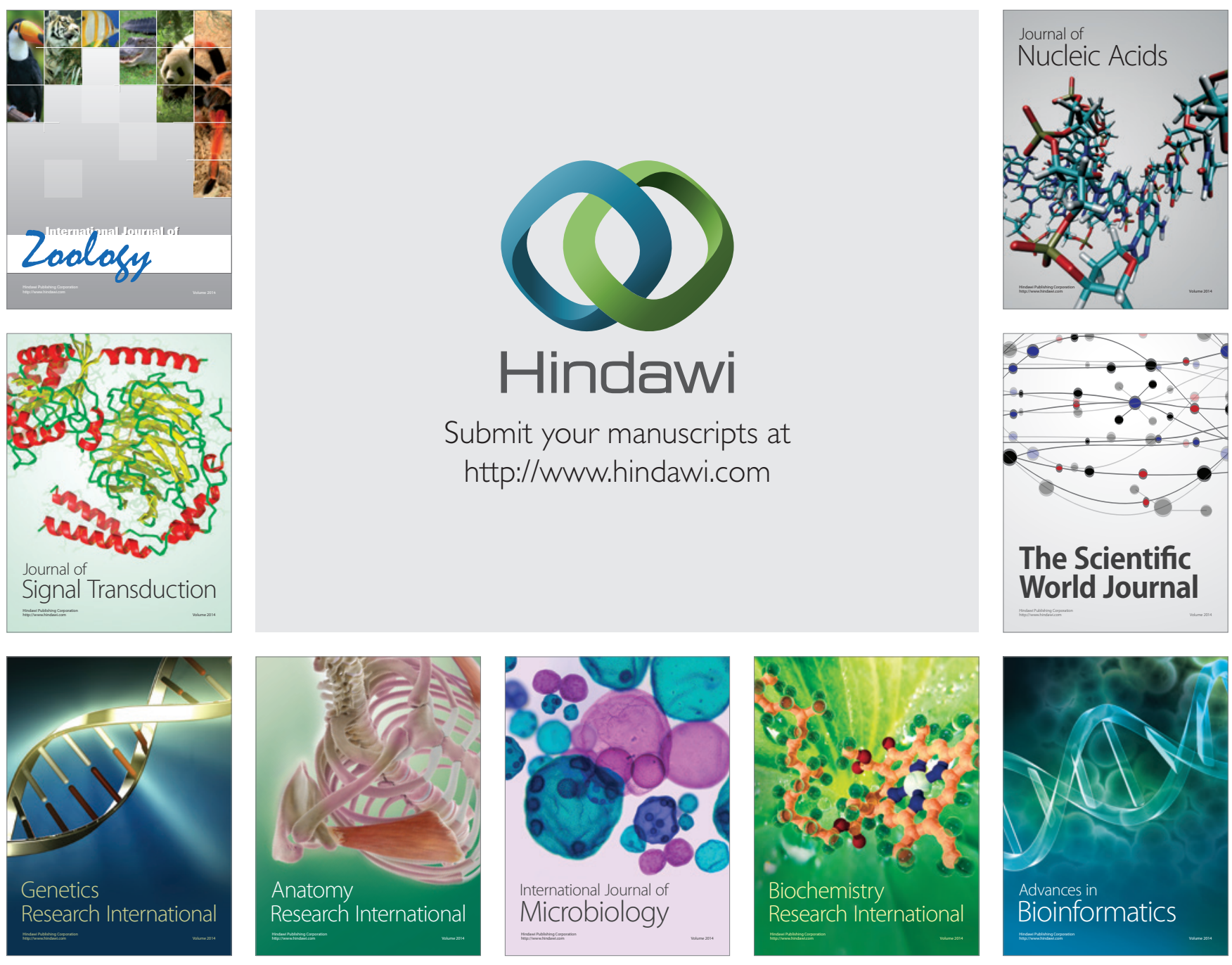

The Scientific World Journal
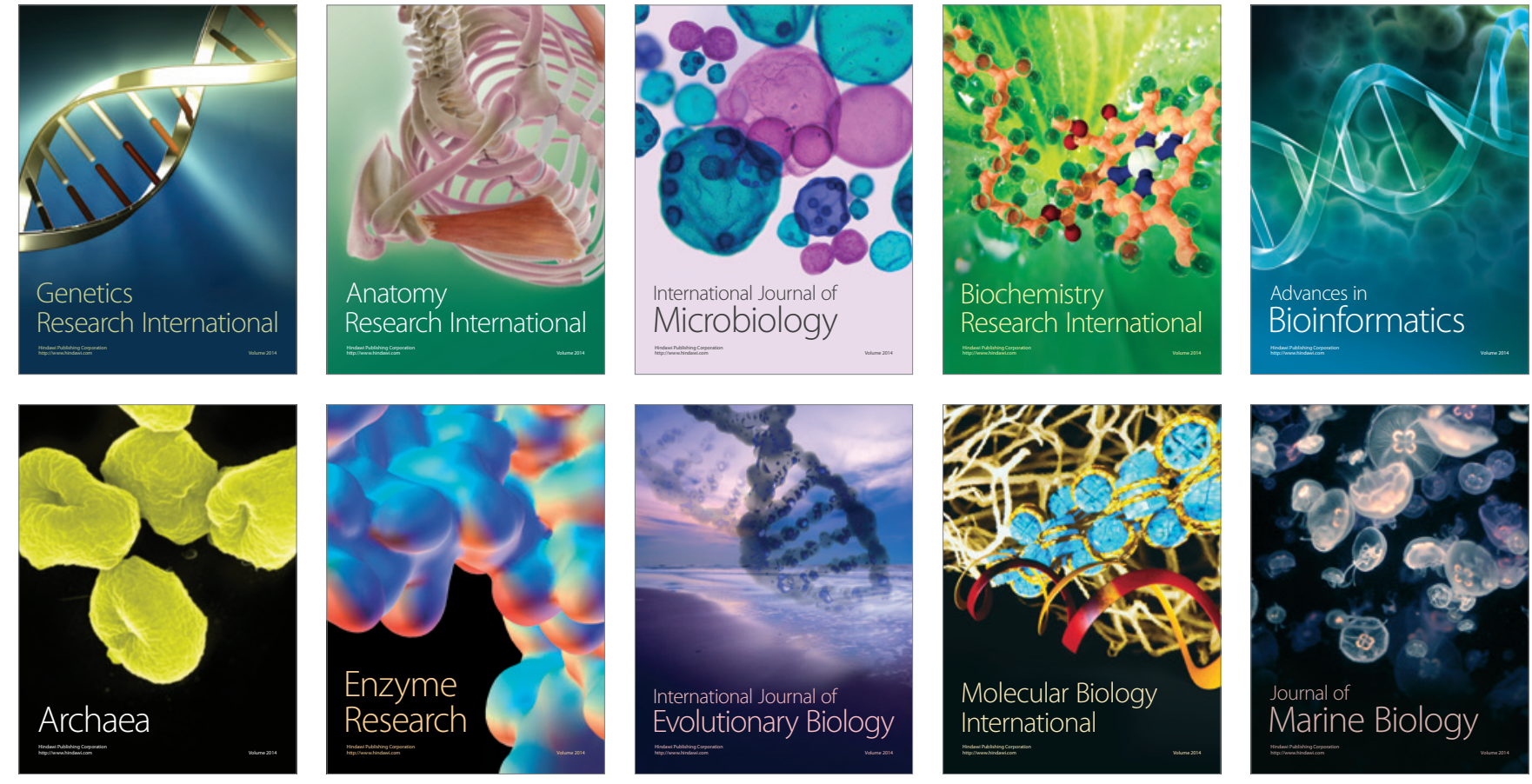